OPEN ACCESS

Edited by:

Daniel Bressington, Hong Kong Polytechnic University,

Hong Kong

Reviewed by:

Laoise Jean Renwick,

University of Manchester,

United Kingdom

Edwin Lee,

The University of Hong Kong,

Hong Kong

Kit Wa Sherry Chan,

The University of Hong Kong,

Hong Kong

*Correspondence:

Roberto Mediavilla,

roberto.mediavilla.torres@gmail.com

Specialty section:

This article was submitted to

Schizophrenia

a section of the journal

Frontiers in Psychiatry

Received: 10 February 2019

Accepted: 16 April 2019

Published: 02 May 2019

Citation:

Mediavilla R, Muñoz-Sanjose A,

Rodriguez-Vega B, Bayon C, Lahera G, Palao A and Bravo MF (2019) Mindfulness-Based Social

Cognition Training (SocialMind) for People With Psychosis:

A Feasibility Trial.

Front. Psychiatry 10:299.

doi: 10.3389/fpsyt.2019.00299

\section{Mindfulness-Based Social Cognition Training (SocialMind) for People With Psychosis: A Feasibility Trial}

\author{
Roberto Mediavilla ${ }^{1,2 *}$, Ainoa Muñoz-Sanjose ${ }^{1,3}$, Beatriz Rodriguez-Vega ${ }^{1,3,4}$, \\ Carmen Bayon 1,3,4, Guillermo Lahera ${ }^{5,6}$, Angela Palao ${ }^{1,3,4}$ and Maria Fe Bravo-Ortiz ${ }^{1,3,4}$ \\ ${ }^{1}$ Hospital La Paz Institute for Health Research (IdiPAZ), Madrid, Spain, ${ }^{2}$ School of Psychology, National University of Distance \\ Education (UNED), Madrid, Spain, ${ }^{3}$ Department of Psychiatry, Clinical Psychology and Mental Health, La Paz University Hospital, \\ Madrid, Spain, ${ }^{4}$ School of Medicine, Autonomous University of Madrid (UAM), Madrid, Spain, ${ }^{5}$ School of Medicine, University of \\ Alcala (UAH), Madrid, Spain, ${ }^{6}$ Mental Health Networking Biomedical Research Centre (CIBERSAM), Madrid, Spain
}

Introduction: Difficulties in social functioning are common among people with psychosis. Negative symptoms such as blunted affect or social withdrawal are often linked to these difficulties and worsen real-life outcomes. One important dimension associated with social functioning is social cognition, which refers to the psychological processes that are necessary to perceive, encode, store, retrieve, and regulate social information. Mindfulnessbased interventions for people with psychosis are safe and effective in improving anxiety and depressive symptoms; however, no mindfulness-based interventions addressing social cognition have yet been developed.

Method: A pilot, single-arm, nonrandomized, noncontrolled feasibility trial is proposed. The main objectives are to assess the tolerability of mindfulness-based social cognition training (SocialMind) and to test the feasibility of a further randomized controlled trial.

Results: A final sample of 25 outpatients with schizophrenia spectrum disorders was included. Attrition rate was lower than usual for this population, and most participants completed the training. No adverse effects were identified in terms of hospitalizations, emergency room visits, dissociative and psychotic symptoms, or state of anxiety during the sessions.

Conclusion: This is the first implementation of SocialMind, which is the first mindfulnessbased social cognition training. It is well tolerated by participants with schizophrenia spectrum disorders, and a further randomized controlled trial is proposed for people who have suffered their first episode of psychosis within the past 5 years.

Clinical Trial Registration: www.ClinicalTrials.gov, identifier NCT03434405.

Keywords: mindfulness, social cognition, psychosis, schizophrenia, feasibility, clinical trial, SocialMind

\section{INTRODUCTION}

People suffering from psychosis frequently find it difficult to establish or maintain relationships with others or to engage in community activities $(1,2)$. These deficits are present even in high-risk or prodromal states (3), strengthening the role of social functioning as a core therapy outcome $(4,5)$. Social cognition is defined as "the psychological processes that are involved in the perception, 
encoding, storage, retrieval, and regulation of information of other people and ourselves" (6). It is associated with community functioning, with estimated average correlations ranging from 0.31 to 0.48 (7), and its deficits can also be observed in the early stages of the psychotic process (8).

Antipsychotic medication improves positive and general psychiatric symptoms, but it has limited effect against negative syndrome, which consists of blunted affect, apathy, lack of spontaneity, and social withdrawal (9). These symptoms often respond to some psychological interventions, such as assertive community treatment, cognitive remediation, social skills training, or cognitive-behavioral therapy (10); hence, they are usually offered along with antipsychotic treatment (11). Many cognitive-behavioral interventions are now available for people with psychosis. They have evolved from targeting only emotional distress to focusing on psychotic symptoms (10), and have been shown to be effective in improving these symptoms (12) but unable to achieve changes in real-life outcomes (13). These psychotherapeutic approaches emphasize the effort the person needs to make to modify some thoughts, feelings, or behaviors that are harmful: a rationale that fits within an illness-centered framework. In contrast, third-wave cognitive-behavioral interventions are person-centered, emphasize contextual and experiential (rather than behavioral) changes, and explicitly target the functional dimension of psychological phenomena $(14$, p. 880$)$.

Mindfulness-based interventions (MBIs) have gathered strong empirical support for both physical conditions, such as cancer, chronic pain, or cardiovascular disease (15), and mental health problems, such as anxiety, depression, addictive behavior, or schizophrenia spectrum disorders (SSDs) (16). MBI trainees learn attentional strategies that promote awareness of the present moment, as well as cultivate a curious nonjudgmental attitude towards their own experience. This modification of the attentional process fosters a different relationship with symptoms and is one of the active constituents for distress reduction and functional recovery $(17,18)$.

Proliferation of MBIs for people with psychosis have drawn attention to the adverse effects that may emerge, such as dissociative and anxiety symptoms or psychotic-like experiences (19). A recent systematic review and meta-analysis of randomized controlled trials (RCTs) concludes that MBIs are well tolerated by people with SSDs and can be implemented in addition to pharmacological treatment (20). Furthermore, mindfulness training might improve both negative (21) and depressive (22) symptoms.

SocialMind is a mindfulness-based social cognition training with the aim of improving social functioning of people who have suffered at least one episode of psychosis. It is a novel, complex intervention tailored for people with significant levels of distress; furthermore, professionals who implement the intervention need to be experienced both in the field of psychosis and in the teaching of mindfulness techniques. A first approach to SocialMind is thus required in order to explore whether it is safe and well tolerated, participants adhere to the training, and teachers comply with the intervention manual. A feasibility trial allows us to test the hypothesis that SocialMind is acceptable and tolerable for people with psychosis in terms of adverse effects, participant satisfaction, and attrition rates (23). Further, recruitment rates will provide some indirect evidence regarding the power to conduct a further RCT with parallel groups (SocialMind versus active comparator).

\section{MATERIALS AND METHODS}

\section{Study Design and Participants}

It is a pilot, open-label, single-group, nonrandomized, noncontrolled feasibility trial. Participants were recruited from the Psychiatry, Clinical Psychology, and Mental Health Department of La Paz University Hospital in Madrid (Spain) during January and February 2018. All were engaged in either pharmacological treatment, psychosocial treatment, or both. People with a duration of psychosis of less than 5 years were not eligible, as they will be contacted to enroll in the upcoming RCT. The research was approved by the La Paz University Hospital Research Ethics Committee (identifier PI-3066) and registered under ClinicalTrials.gov, identifier NCT03434405.

Inclusion criteria were as follows:

(1) Between 18 and 60 years of age,

(2) Diagnosis of SSD according to the Diagnostic and Statistical Manual of Mental Disorders, 5th Edition (DSM-5),

(3) A Clinical Global Impression (CGI) (24) score equal to or less than four (moderately ill), and

(4) Signed informed consent.

Exclusion criteria were as follows:

(1) First hospitalization, first visit to mental health services with positive symptoms, or first appearance of positive symptoms confirmed by an informant after January 2013;

(2) Intellectual disability plus impaired function prior to disorder onset,

(3) Generalized developmental disorder; and

(4) Substance-related disorder (except for nicotine) according to DSM-5.

\section{Instruments}

Symptom Checklist 90-Revised (SCL-90-R) (25). This instrument consists of a list of 90 symptoms from nine different domains of psychopathology (depression, anxiety, paranoia, psychoticism, etc). The individual has to rate how he or she experienced each symptom during the last week. Nine domain-specific scores are provided, as well as three general indexes. The Spanish version of SCL-90-R has high internal consistency (Cronbach's alpha from 0.81 to 0.90 ) and good convergent and criterion validity, and it is very sensitive for detecting changes (26).

Dissociative Experiences Scale II (DES-II) (27). This scale explores the amount of time a person has a certain experience (i.e., the experience of driving somewhere and not recalling how one got there). There are 28 experiences to be scored from $0 \%$ to $100 \%$ of the time. The final score is an average percentage of time. The Spanish version has good internal consistency (Cronbach's alpha $=0.91$ ) and detects differences between people with schizophrenia and nonclinical samples (28). 
State-Trait Anxiety Inventory-State subscale (STAI-S) (29). The individual has to rate his or her degree of anxiety at the moment of completing the scale. The score ranges from 0 to 60. The Spanish version (30) has high internal consistency for clinical samples (Cronbach's alpha $=0.98$ ) and good test-retest reliability $(r=0.93)(31)$; furthermore, scores are very sensitive to stressful environments (32).

Positive and Negative Syndrome Scale (PANSS) (33). This scale explores three main dimensions through a semistructured interview: positive syndrome (PANSS-P), negative syndrome (PANSS-N), and general psychopathology (GP). Values range from 1 ("absent") to 7 ("extreme"), and final scores range from 7 to 49 for PANSS-P and PANSS-N and from 16 to 112 for GP. Subscales from the Spanish version are strongly associated with the original version ( $r=0.92$ for PANSS-P and $r=0.83$ for PANSS-N), with item correlations ranging from $r=0.64$ to $r=$ 0.97 and high interrater reliability $(\mathrm{r}=0.81)(34)$.

Personal and Social Performance (PSP) scale (35). This scale explores four domains of social functioning, namely, self-care, social relationships, social activities, and disruptive and aggressive behavior. The final score ranges from 0 to 100. The Spanish version of the PSP is reliable and has high internal consistency (Cronbach's alpha $=0.87)$ and excellent test-retest reliability $(\mathrm{r}=$ 0.98); moreover, it comprises one single component that explains $73 \%$ of the variance in social functioning (36).

Client Satisfaction Questionnaire (CSQ-8) (37). This eightitem instrument explores how much a person is satisfied with different domains of healthcare services. A final score between 8 and 32 is provided. The Spanish version has levels of internal consistency similar to the original version (Cronbach's alpha = 0.90); however, final scores appear to be influenced by job status and education level (38). It has been previously used in feasibility trials of MBIs for psychosis (39).

SocialMind teachers' checklist. This instrument consists of two parts. The first is inspired by the assessment of protocol compliance in Social Cognition and Interaction Training (SCIT) (40). Raters must check if teachers adhere to the SocialMind manual and complete eight items that range from 0 to 2 points, with higher values indicating more adherence. The second part is the Mindfulness-Based Interventions: Teaching Assessment Criteria (MBI:TAC) (41), which comprises six domains that should be addressed in each session, such as embodiment of mindfulness, correct guidance, or holding the group environment. Teachers can obtain a score between 1 ("incompetent: absence of key features or highly inappropriate performance") and 6 points ("advanced: excellent teaching practice, or very good even in the face of participant difficulties"). Assessments were made after checking video recordings of the sessions.

\section{Procedure \\ Assessment}

The pre-intervention assessment was completed within 2 weeks prior to the start of SocialMind training. It consisted of a sociodemographic interview, followed by PANSS and PSP (clinical interview) and by SCL-90-R and DES-II (self-reported instruments). The post-intervention assessment was carried out within 2 weeks after the end of SocialMind training and included PANSS, PSP, SCL-90-R, DES-II, and CSQ-8. STAI-S was completed before and after each session. Raters were psychologists and intern psychiatrists who were not SocialMind teachers.

For the assessment of the teachers, they watched video recordings of sessions in which they had not participated. This ensured that raters were familiarized with the intervention and avoided self-rating.

\section{Intervention}

SocialMind is an intervention for people with psychosis designed by the authors and presented here for the first time. It is mindfulness-based social cognition training that highlights the importance of cultivating an acceptance-based, nonjudgmental approach to one's experience. It incorporates formal meditation practices tailored for people with psychosis and social cognition exercises inspired by SCIT (40). Practices of formal meditation consist of focusing attention on a chosen object either inside (i.e., breathing, weight) or outside (i.e., noises, smells) the body, as well as compassion practices such as loving-kindness or soothing touch meditations. They are inspired in practices of three formal mindfulness programs: the Mindfulness-Based Stress Reduction program (MBSR) (18), mindfulness-based cognitive therapy (MBCT) (42), and the Mindful Self-Compassion program (MSC) (43). SocialMind teachers were also certified teachers of these programs, and recommendations of mindfulness programs for psychosis were considered $(19,44)$. Social cognition training includes attributional bias exercises, mentalizing abilities (i.e., theory of mind), or emotion perception and social cues tasks. The full intervention consists of eight weekly sessions, followed by four fortnightly sessions and five monthly sessions. Each lasts $90 \mathrm{~min}$, and groups are made up of a maximum of 15 participants. For the present study, only weekly sessions were performed (for an example of one of these sessions, see Figure 1). One morning and one evening training were scheduled, so participants could choose according to their preferences. The principal teacher (AM) led both groups, with one co-therapist in the mornings (BR) and one in the evenings (AP).

\section{Statistical Analysis}

According to some authors, null-hypothesis contrasts are not necessary in feasibility trials, as they are not designed to test effectiveness of a certain intervention $(45,46)$. Nonetheless, this trial needs to prove that SocialMind is safe and well tolerated by people with psychosis, and not being able to establish statistical inferences has also been reported as a limitation in feasibility trials $(39,47)$.

In order to detect moderate-to-large effect sizes (Cohen's $\mathrm{d}=$ $0.7)$ in indicators of adverse effects with a $95 \%$ of probability (1 $B=0.95)$ and a type I error of $5 \%(\alpha=0.05)$, a sample of $\mathrm{N}=25$ is needed to conduct nonsuperiority tests. First, chi-squared and Mann-Whitney tests were performed to check for equivalence of baselines in morning and evening trainings. Then, the KolmogorovSmirnov test revealed if there was any non-normal distribution across main variables. To calculate pre-post differences, a pairedsample one-tailed t-test was carried out when the sample followed a normal distribution and there were no outliers within the 


\begin{tabular}{|c|c|}
\hline Welcome meditation (3') & 3-min guided meditation \\
\hline Summary of previous session (1') & Brief summary of the contents of session 4 \\
\hline Home-practice review (5') & $\begin{array}{l}\text { Experience during informal (i.e., mindful walking) and formal (i.e., recordings of guided meditations) practices during the week. Focus on any difficult } \\
\text { with training. }\end{array}$ \\
\hline $\operatorname{Exposition}\left(10^{\prime}\right)$ & $\begin{array}{l}\text { Self-compassion and loving kindness promote health and wellbeing. The importance of being aware of self-criticism and judging attitudes through } \\
\text { oneself and others. }\end{array}$ \\
\hline \multirow{3}{*}{ Practices (25') } & Soothing touch: Participants are encouraged to find a part of their body where a gentle touch is soothing. \\
\hline & $\begin{array}{l}\text { Mindful movements: Participants perform simple exercises consisting of moving their arms up and down, or stretching their bodies, with the instruction } \\
\text { of keeping full awareness. }\end{array}$ \\
\hline & Loving kindness: teachers include phrases that promote a mental state of unselfish and unconditional kindness to all beings, especially oneself. \\
\hline \multirow{2}{*}{ Exercises (20') } & $\begin{array}{l}\text { Emotion recognition: Participants are encouraged to identify basic emotions in a series of pictures. They also discuss how they feel and how would react } \\
\text { to each facial expression. }\end{array}$ \\
\hline & $\begin{array}{l}\text { Attributional style: Teachers read some stories out loud. Participants are invited to think about the characters' performance and to imagine how they } \\
\text { would feel. }\end{array}$ \\
\hline Summary and closure $\left(10^{\prime}\right)$ & $\begin{array}{l}\text { Teachers summarize today's session. Participants and teachers summarize in one short sentence what they have learned or how the session made them } \\
\text { feel }\end{array}$ \\
\hline \multirow[b]{2}{*}{ Home-practice presentation ( $\left.5^{\prime}\right)$} & Formal practices. Teachers give participants two new audio recordings (soothing touch and loving kindness). \\
\hline & $\begin{array}{l}\text { Informal practices. Participants are told to practice mindful engagement in daily activities (driving, eating, taking a shower...), self-care (enjoy a meal or } \\
\text { a walk), self-compassion (kind inner talk) and kind gestures (i.e., to hold the door) during the week. }\end{array}$ \\
\hline
\end{tabular}

dependent variable; for non-normal distributions, the one-tailed Wilcoxon signed rank test for matched pairs was used. Data were analyzed with IBM ${ }^{\circledR}$ SPSS ${ }^{\circledR}$ Statistics Version 21.

\section{RESULTS}

Twenty-seven participants signed informed consent and completed pretreatment assessment. Two of them found a job before groups were formed. Characteristics of the remaining 25 participants are shown in Table 1. There were no differences between morning and evening training in age, gender, educational level, job status, and symptoms (SCL-90-R, PANSS, DES-II, STAI-S). Scores on PSP social activities, $Z=-2.622, p<$ 0.010 , were better among participants of the morning sessions. All interval variables were normally distributed, except for PSP self-care in pretreatment $(\mathrm{D}=1.390, p<0.042)$ and posttreatment $(\mathrm{D}=1.605, p<0.012)$ and PSP aggressive behavior at 8 weeks $(\mathrm{D}=1.605, p<0.012)$. PSP-T had a mean of 57.40 $(\mathrm{SD}=14.58)$ in pretreatment and a mean of $57.44(\mathrm{SD}=$ 10.72) in post-treatment, and its distribution was normal at both time points.

\section{Feasibility}

The flowchart is shown in Figure 2. Fifteen participants were allocated to the morning intervention, and 10 participants were allocated to the evening intervention. The attrition rate was $15 \%$. The remaining participants attended six or more sessions and
TABLE 1 | Characteristics of the participants ( $N=25)$.

\begin{tabular}{lc}
\hline & N (\%)/M (SD) \\
\hline Age in years & $45(9.38)$ \\
Gender & \\
Women & $11(44 \%)$ \\
Men & $14(56 \%)$ \\
Educational level & $3(12 \%)$ \\
Primary (6-9 years) & $18(72 \%)$ \\
Secondary (10-14 years) & $4(16 \%)$ \\
University (>15 years) & \\
Job status & $6(24 \%)$ \\
Employed & $7(28 \%)$ \\
Unemployed & $11(44 \%)$ \\
Disability insurance & $1(4 \%)$ \\
Student & \\
Marital status & $20(80 \%)$ \\
Single & $5(20 \%)$ \\
Married & $18.4(10.9)$ \\
Duration of illness in years & $3.04(3.21)$ \\
Number of hospitalizations & \\
DSM-5 diagnosis & $23(92 \%)$ \\
Schizophrenia (295.90) & $1(4 \%)$ \\
Schizoaffective disorder (295.70) & $1(4 \%)$ \\
Schizophrenia spectrum disorder & \\
not otherwise specified (298.9) & \\
PANSS score & $12.28(3.21)$ \\
Positive syndrome (P) & $16.28(5.20)$ \\
Negative syndrome (N) & $26.12(6.04)$ \\
General psychopathology (GP) & \\
\hline
\end{tabular}

PANSS, Positive and Negative Syndrome Scale for schizophrenia; DSM-5, Diagnostic and Statistical Manual of Mental Disorders, 5th Edition. 


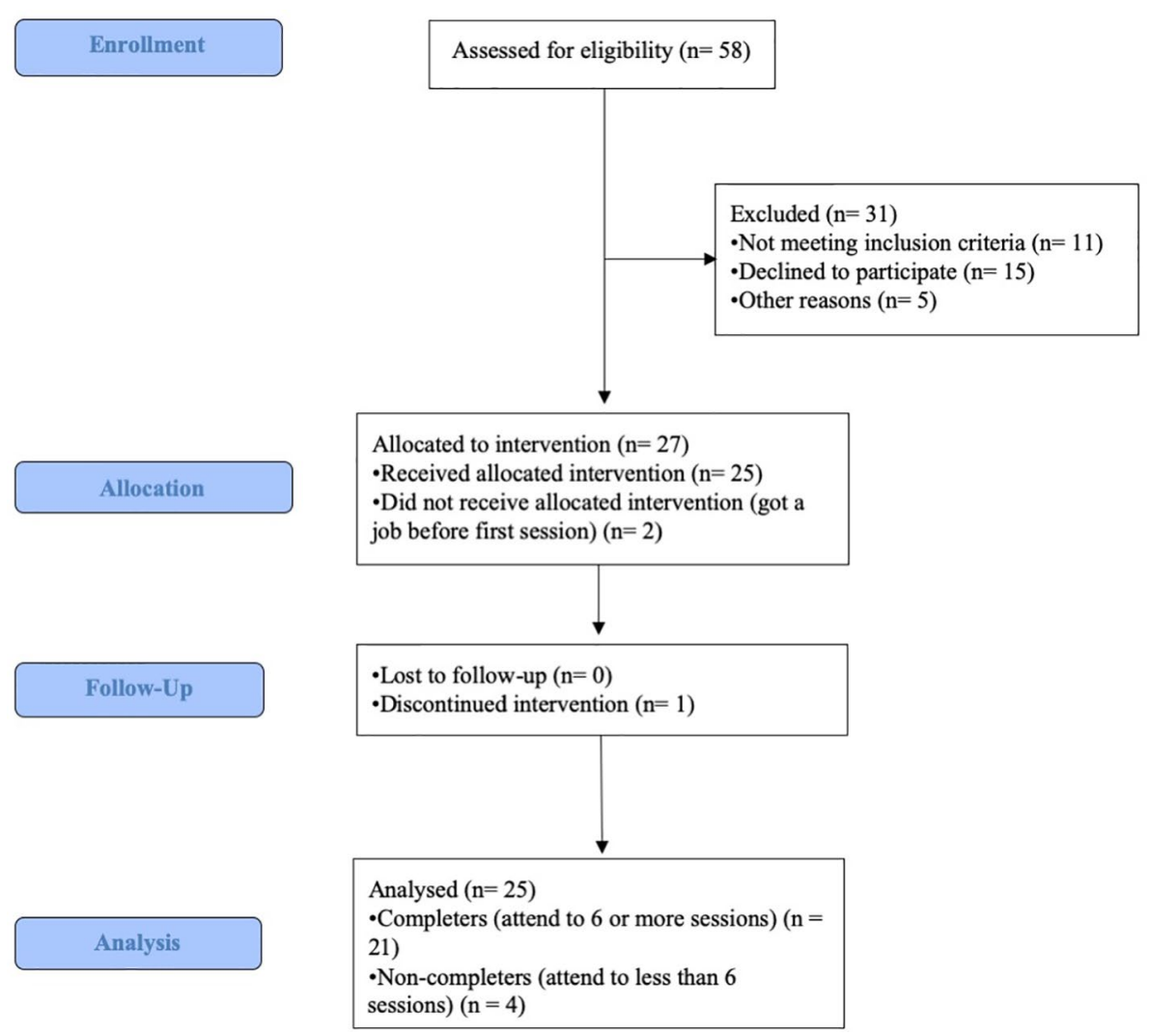

FIGURE 2 | CONSORT flowchart.

therefore completed the intensive part of SocialMind training. CSQ- 8 scores reveal a median satisfaction of 3 out of 4 points.

\section{Tolerability and Adverse Effects}

None of the participants were hospitalized, went to the emergency room, or asked for an unscheduled appointment with his or her psychiatrist during the 8 weeks of training. After session number 4 , one participant stopped coming to the training. He said he was not obtaining any benefit from the intervention. We did not find any indicator of adverse effects in his post-treatment assessment.

Table 2 shows general symptomatology (SCL-90-R, PANSS), within-session state anxiety (STAI-S), and dissociative experiences (DES-II) before and after SocialMind training. There was no significant increase in symptoms in any of these indicators; however, one participant reported a 3-point (4\%) increase in STAI-S after session number 5 .

\section{Teachers' Competence and Adherence to SocialMind Manual}

Scores on MBI:TAC ranged from 5 ("competent") to 6 ("proficient") points, which means that teachers present only minor problems and/or inconsistencies. Checklist scores ranged from 1 to 2 points, with a median value of 2 ("full compliance") and a mean value of $1.90(\mathrm{SD}=0.31)$.

\section{DISCUSSION}

This study explores a new person-centered, group mindfulnessbased social cognition training (SocialMind) developed for people with SSDs. We performed a feasibility trial with two goals: to evaluate acceptability and tolerability of SocialMind training and to confirm that a RCT can be implemented.

We did not find any increase in psychotic symptoms, nonpsychotic symptoms, dissociative experiences, hospitalization rates, or functional impairment after SocialMind intervention. Most participants completed the training, and the attrition rate was low compared to previous reports (48). This can be considered an indicator of satisfaction with the intervention, which is also supported by scores on the Client Satisfaction Questionnaire. Recent reviews emphasize that adverse effects may be reported mainly during silence retreats or intensive meditation trainings, and in the context of programs that have not been adapted to people with psychosis $(19,20)$. SocialMind teachers are psychiatrists certified as mindfulness teachers who have experience with severe mental disorders, which is in keeping with Chadwick's (44) recommendations. Meditation practices have been specifically adapted for people with SSDs: they are shorter than usual, with simple and concrete instructions, limited periods of silence, and interpersonal practices introduced progressively. 
TABLE 2 | Pre-post differences (Student's t-test) on indicators of adverse effects (higher scores in "mean pre" and "mean post" indicates higher presence of symptoms).

\begin{tabular}{|c|c|c|c|c|}
\hline Domain & Mean pre & Mean post & Mean difference (SD) & $95 \%$ one-sided $\mathrm{Cl}$ \\
\hline \multicolumn{5}{|l|}{ SCL-90-R } \\
\hline Somatization & 0.81 & 0.72 & $0.10(0.55)$ & {$[-0.09, \infty)$} \\
\hline Obsession-compulsion & 1.22 & 1.03 & $0.19(0.62)$ & {$[-0.02, \infty)$} \\
\hline Interpersonal sensitivity & 1.27 & 1.14 & $0.13(0.49)$ & {$[-0.04, \infty)$} \\
\hline Depression & 1.11 & 0.87 & $0.24(0.51)$ & {$[0.06, \infty)$} \\
\hline Anxiety & 1.10 & 0.99 & $0.10(0.44)$ & {$[-0.05, \infty)$} \\
\hline Hostility & 1.03 & 0.97 & $0.06(0.41)$ & {$[-0.08, \infty)$} \\
\hline Phobic anxiety & 1.12 & 0.97 & $0.14(0.47)$ & {$[-0.02, \infty)$} \\
\hline Suspiciousness & 0.97 & 0.98 & $0.00(0.46)$ & {$[-0.16, \infty)$} \\
\hline Psychoticism & 1.11 & 0.98 & $0.12(0.45)$ & {$[-0.03, \infty)$} \\
\hline \multicolumn{5}{|l|}{ PANSS } \\
\hline Positive syndrome & 12.28 & 11.36 & $0.92(3.15)$ & {$[-0.16, \infty)$} \\
\hline Negative syndrome & 16.28 & 15.48 & $0.80(4.49)$ & {$[-0.74, \infty)$} \\
\hline General psychopathology & 26.12 & 25.88 & $0.24(7.60)$ & {$[-2,36, \infty)$} \\
\hline Dissociative symptoms (DES-II) & 9.89 & 10.80 & $-0.90(9.34)^{\mathrm{ns}}$ & {$[-4.10, \infty)$} \\
\hline State anxiety (STAI-S) & 22.00 & 16.26 & $5.74(5.68)$ & {$[3.75, \infty)$} \\
\hline
\end{tabular}

SD, standard deviation; Cl, confidence interval; SCL-90-R, Symptom Checklist 90-Revised; PANSS, Positive and Negative Syndrome Scale; DES-II, Dissociative Experiences Scale II; STAI-S, State-Trait Anxiety Inventory-State.

$n s$, nonsignificant $(p=0.317)$.

In a systematic review, Aust and Bradshaw (49) identified 11 RCTs of interventions for people with SSDs that explicitly incorporated mindfulness elements. Only five of them were mindfulness-based group interventions. Since then, results from another RCT with over 100 participants have been reported (50). Except for Chadwick et al. and Chien and Thompson (51), sample sizes range from 21 to 44 participants. Positive and negative symptoms are the most frequent primary outcomes among these trials; however, a decrease in symptoms does not necessary improve social function (10). Only one study explored changes in general function against an active comparator, and the authors reported a low effect size (51). Interventions need to improve real-life outcomes (5), and it is desirable for this improvement to be at least as significant as with other comparable interventions; therefore, our RCT will compare the effects of SocialMind training over social functioning against an active comparator. The final score of the Personal and Social Performance (PSP) scale will be our primary outcome measure, which is normally distributed and with values similar to the Spanish adaptation in this trial (36). It is not a self-reported measure, so we also expect that social desirability will be kept as low as possible (52).

It is impossible to assert that an RCT can actually be implemented, because participants were not randomized in this feasibility trial; however, recruitment and adherence rates confirm that people with SSDs in our catchment area are interested in enrolling in a clinical trial. Even though it is possible that participants are retained due to certain elements of SocialMind training, it is more likely that they attended simply because an active intervention was offered to them (53). Therefore, similar results of recruitment and adherence can be expected from an RCT with two active intervention arms (SocialMind versus active comparator). If rates are similar, two groups of 10 to 12 people who regularly attend sessions would be formed for each randomization. Effectiveness cannot be explored in a noncontrolled trial, because it is impossible to determine if a change in the outcome variable is caused by the treatment; nonetheless, the purpose of a feasibility trial is not to test effectiveness, so a control group-although desirable-is not necessary. If there had been any major adverse effects, such as visits to the emergency room, hospitalizations, or suicide attempts, either the research team or participants' psychiatrists would have detected them. Similarly, moderate-tolarge increments in psychotic symptoms, anxiety and depressive symptoms, or dissociative experiences would have been detected in $96 \%$ of cases (24 out of 25 participants). Because anxiety symptoms are one of the most frequently reported adverse effects of MBIs in psychosis (19), they were monitored thoroughly, and participants registered their anxiety levels before and after each SocialMind session.

SocialMind does not cause any harm to the participants, and descriptive data even suggest that it may have beneficial effects for anxiety and depressive symptoms. A further RCT needs to address this and should explore if there are any improvements in social functioning. SocialMind is also the first mindfulness-based social cognition training, so several social cognition tasks will complete the assessment protocol to explore their role as moderate variables. In order to maximize the therapeutic potential of the RCT, at least two enhancements can be implemented. First, social cognition and functioning are often affected starting in the early stages of psychosis (8), so it might be optimal to apply this intervention as soon as possible. Second, an extended period of booster sessions may set some learning and help to incorporate formal and informal practices as a habit. Our RCT (ClinicalTrials.gov identifier: NCT03309475) will compare the effectiveness of extended SocialMind training (eight weekly sessions, four fortnightly sessions, and five monthly sessions) versus a psychoeducational multicomponent intervention in people between 16 and 40 years of age who have suffered their first psychotic episode within the last five years. We expect that this early, person-centered, group intervention will improve disturbing symptoms, negative emotions, social function, and quality of life, preventing further psychotic episodes and hospitalizations. 


\section{ETHICS STATEMENT}

This study was carried out in accordance with the recommendations of La Paz University Hospital Research Ethics Committee (PI3066) with written informed consent from all subjects. All subjects gave written informed consent in accordance with the Declaration of Helsinki. The protocol was approved by La Paz University Hospital Research Ethics Committee and registered under ClinicalTrials.gov identifier NCT03434405.

\section{AUTHOR CONTRIBUTIONS}

RM designed the investigation, collected and analyzed the data, and wrote the final version of the manuscript. AM-S designed

\section{REFERENCES}

1. Gayer-Anderson C, Morgan C. Social networks, support and early psychosis: a systematic review. Epidemiol Psychiatr Sci (2013) 22(2):131-46. doi: 10.1017/S2045796012000406

2. Palumbo C, Volpe U, Matanov A, Priebe S, Giacco D. Social networks of patients with psychosis: a systematic review. BMC Res Notes (2015) 8(1):1-12. doi: 10.1186/s13104-015-1528-7

3. Fusar-Poli P, Borgwardt S, Bechdolf A, Addington J, Riecher-Rössler A, Schultze-Lutter F, et al. The psychosis high-risk state: a comprehensive state-of-the-art review. JAMA Psychiatry (2013) 70(1):107-20. doi: 10.1001/ jamapsychiatry.2013.269

4. Couture SM, Penn DL, Roberts DL. The functional significance of social cognition in schizophrenia: a review. Schizophr Bull (2006) 32(suppl.1):4463. doi: 10.1093/schbul/sbl029

5. Fleischhacker WW, Arango C, Arteel P, Barnes TRE, Carpenter W, Duckworth K, et al. Schizophrenia-time to commit to policy change. Schizophr Bull (2014) 40(3) S165-S194. doi: 10.1093/schbul/sbu006

6. Green MF, Horan WP, Lee J. Social cognition in schizophrenia. Nat Rev Neurosci (2015) 16(10):620-31. doi: 10.1038/nrn4005

7. Fett AKJ, Viechtbauer W, Dominguez M, Penn DL, van Os J, Krabbendam L. The relationship between neurocognition and social cognition with functional outcomes in schizophrenia: a meta-analysis. Neurosci Biobehav Rev (2011) 35(3):573-88. doi: 10.1016/j.neubiorev.2010.07.001

8. Healey KM, Bartholomeusz CF, Penn DL. Deficits in social cognition in first episode psychosis: a review of the literature. Clin Psychol Rev (2016) 50:10837. doi: 10.1016/j.cpr.2016.10.001

9. Leucht S, Leucht C, Huhn M, Chaimani A, Mavridis D, Helfer B, et al. Sixty years of placebo-controlled antipsychotic drug trials in acute schizophrenia: systematic review, Bayesian meta-analysis, and meta-regression of efficacy predictors. Am J Psychiatry (2017) 174(10):927-42. doi: 10.1176/appi. ajp.2017.16121358

10. Mueser KT, Deavers F, Penn DL, Cassisi JE. Psychosocial treatments for schizophrenia. Annu Rev Clin Psychol (2013) 9:465-97. doi: 10.1146/ annurev-clinpsy-050212-185620

11. Kreyenbuhl J, Buchanan RW, Dickerson FB, Dixon LB. The schizophrenia patient outcomes research team (PORT): updated treatment recommendations 2009. Schizophr Bull (2010) 36(1):94-103. doi: 10.1093/ schbul/sbp 130

12. Jauhar S, McKenna PJ, Radua J, Fung E, Salvador R, Laws KR. Cognitivebehavioural therapy for the symptoms of schizophrenia: systematic review and meta-analysis with examination of potential bias. Br J Psychiatry (2014) 204(1):20-9. doi: 10.1192/bjp.bp.112.116285

13. Laws KR, Darlington N, Kondel TK, McKenna PJ, Jauhar S. Cognitive behavioural therapy for schizophrenia-outcomes for functioning, distress and quality of life: a meta-analysis. BMC Psychol (2018) 6(1):1-10. doi: $10.1186 /$ s40359-018-0243-2 the intervention, led SocialMind groups, and contributed to the final version of the manuscript. BR-V, CB, and AP developed the intervention, were teachers in SocialMind groups, and contributed to the final version of the manuscript. GL developed the intervention and contributed to the final version of the manuscript. $\mathrm{MB}$ monitored the process and contributed to the final version of the manuscript. All the authors read and approved the final version of the manuscript.

\section{FUNDING}

The research was funded by the European Regional Development Fund (ERDF) and the Institute of Health Carlos III (ISCIII) (grant number PI 17/00768).

14. Hayes SC. Acceptance and commitment therapy, relational frame theory and the third wave of behavioral and cognitive therapies-republished article. Behav Ther (2016) 47(6):869-85. doi: 10.1016/j.beth.2016.11.006

15. Gotink RA, Chu P, Busschbach JJV, Benson H, Fricchione GL, Hunink MG. Standardised mindfulness-based interventions in healthcare: an overview of systematic reviews and meta-analyses of RCTs. PLoS One (2015) 10(4):e0124344. doi: 10.1371/journal.pone.0124344. (Retraction in: PLoS One (2019) 14(4):e0215608. doi: 10.1371/journal.pone.0215608)

16. Goldberg SB, Tucker RP, Greene PA, Davidson RJ, Wampold BE, Kearney DJ, et al. Mindfulness-based interventions for psychiatric disorders: a systematic review and meta-analysis. Clin Psychol Rev (2018) 59:52-60. doi: 10.1016/j. cpr.2017.10.011

17. Abba N, Chadwick P, Stevenson C. Responding mindfully to distressing psychosis: a grounded theory analysis. Psychother Res (2008) 18(1):77-87. doi: 10.1080/10503300701367992

18. Kabat-Zinn J. Full catastrophe living: The program of the stress reduction clinic at the University of Massachusetts Medical Center. New York: Delacorte Press (1994).

19. Van Gordon W, Shonin E, Garcia-Campayo J. Are there adverse effects associated with mindfulness? Aust N Z J Psychiatry (2017) 51(10):977-9. doi: $10.1177 / 0004867417716309$

20. Cramer H, Lauche R, Haller H, Langhorst J, Dobos G. Mindfulness- and acceptance-based interventions for psychosis: a systematic review and metaanalysis. GAHMJ (2016) 5(1):30-43. doi: 10.7453/gahmj.2015.083

21. Khoury B, Lecomte T, Gaudiano BA, Paquin K. Mindfulness interventions for psychosis: a meta-analysis. Schizophr Res (2013) 150(1):176-84. doi: 10.1016/j.schres.2013.07.055

22. Louise S, Fitzpatrick M, Strauss C, Rossell SL, Thomas N. Mindfulness- and acceptance-based interventions for psychosis: our current understanding and a meta-analysis. Schizophr Res (2018) 192:57-63. doi: 10.1016/j. schres.2017.05.023

23. Van der Valk R, Van de Waerdt S, Meijer C, Van den Hout I, De Haan L. Feasibility of mindfulness-based therapy in patients recovering from a first psychotic episode: a pilot study. Early Intev Psychiatry (2013) 7(1):64-70. doi: 10.1111/j.1751-7893.2012.00356.x

24. Haro JM, Kamath SA, Ochoa S, Novick D, Rele K, Fargas A, et al. The Clinical Global Impression-Schizophrenia scale: a simple instrument to measure the diversity of symptoms present in schizophrenia. Acta Psychiatr Scand (2003) 107(416):16-23. doi: 10.1034/j.1600-0447.107. s416.5.x

25. Derogatis LR. Symptom Checklist-90-Revised. SCL-90-R. New Jersey: NCS Pearson (1979).

26. Gonzalez de Rivera JL, de las Cuevas C, Rodriguez-Abuin M, RodríguezPulido F. SCL-90-R. Cuestionario de 90 Síntomas. Madrid: TEA Ediciones (2002).

27. Carlson EB, Putnam FW. An update on the Dissociative Experiences Scale. Dissociation: Progress in the Dissociative Disorders (1993) 6(1):16-27. 
28. Icaran E, Colom R, Orengo F. Validation study of the Dissociative Experiences Scale in Spanish population sample. Actas Luso Esp Neurol Psiquiatr (1996) 24(1):7-10.

29. Spielberger RD, Gorsuch RL, Lushene RE. STAI. Manual of the State-Trait Anxiety Inventory (Self Evaluation Questionnaire). California: Consulting Psychologists Press (1970).

30. Spielberger CD, Gorsuch RL, Lushene R. Manual del Cuestionario de Ansiedad Estado/Rasgo (STAI). Madrid: TEA Ediciones (1982).

31. Ortuño-Sierra J, García-Velasco L, Inchausti F, Debbané M, Fonseca-Pedrero E. Nuevas aproximaciones en el estudio de las propiedades psicométricas del STAI. Actas Esp Psiquiatr (2016) 44(3):83-92. Available from: https://www. actaspsiquiatria.es/repositorio/18/101/ESP/18-101-ESP-83-92-488201.pdf.

32. Guillen-Riquelme A, Buela-Casal G. Actualización psicométrica y funcionamiento diferencial de los ítems en el State Trait Anxiety Inventory (STAI). Psicothema (2011) 23(3):510-5. Available from: papers3:// publication/uuid/17223759-F193-4298-9F5F-398CB3DCF1EBR.

33. Kay SR, Fiszbein A, Opler LA. The Positive and Negative Syndrome Scale (PANSS) for schizophrenia. Schizophr Bull (1987) 13(2):261-76. doi: 10.1093/schbul/13.2.261

34. Kay SR, Fiszbein A, Vital-Herne M, Silva Fuentes L. The Positive and Negative Syndrome Scale-Spanish adaptation. J Nerv Ment Dis (1990) 178:510-7. Available from: https://journals.lww.com/jonmd/Citation/ 1990/08000/The_Positive_and_Negative_Syndrome_Scale_Spanish.7.aspx. doi: 10.1097/00005053-199008000-00007

35. Morosini PL, Magliano L, Brambilla L, Ugolini S, Pioli R. Development, reliability and acceptability of a new version of the DSM-IV Social and Occupational Functioning Assessment Scale (SOFAS) to assess routine social functioning. Acta Psychiatr Scand (2001) 101(4):323-9. doi: 10.1034/j.1600-0447.2000.101004323.x

36. Garcia-Portilla MP, Saiz PA, Bousoño M, Bascaran MT, Guzmán-Quilo C, Bobes J. Validación de la versión Española de la escala de Funcionamiento Personal y Social en pacientes ambulatorios con esquizofrenia estable o inestable. Rev Psiquiatr Salud Ment (2011) 4(1):9-18. doi: 10.1016/j. rpsm.2010.11.003

37. Attkisson CC, Zwick R. The Client Satisfaction Questionnaire: psychometric properties and correlations with service utilization and psychotherapy outcome. Eval Program Plann (1982) 5(3):233-7. doi: 10.1016/0149-7189(82)90074-X

38. Roberts RE, Attkinson CC, Mendias RM. Assessing the Client Satisfaction Questionnaire in English and Spanish. Hispanic J Behav Sci (1984) 6(4):385-95. doi: 10.1177/07399863840064004

39. MacDougall A, Price E, Vandermeer M, Lloyd C, Bird R, Sethi R, et al. Youth-focused group mindfulness-based intervention in individuals with early psychosis: a randomized pilot feasibility study. Early Interv Psychiatry (2018) 1-6. doi: 10.1111/eip.12753

40. Combs DR, Adams SD, Penn DL, Roberts D, Tiegreen J, Stem P. Social Cognition and Interaction Training (SCIT) for inpatients with schizophrenia spectrum disorders: preliminary findings. Schizophr Res (2007) 91(1-3):112-6. doi: 10.1016/j.schres.2006.12.010
41. Crane RS, Eames C, Kuyken W, Hastings RP, Williams JMG, Bartley T, et al. Development and validation of the Mindfulness-Based InterventionsTeaching Assessment Criteria (MBI:TAC). ASMNT (2013) 20(6):681-8. doi: $10.1177 / 1073191113490790$

42. Segal ZV, Williams JMG, Teasdale JD. Mindfulness-based cognitive therapy for depression. $2^{\text {nd }}$ Edition. New York: The Guilford Press (2013).

43. Germer CK, Neff KD. Self-compassion in clinical practice. J Clin Psychol (2013) 69(8):856-67. doi: 10.1002/jclp.22021

44. Chadwick P. Mindfulness for psychosis. Br J Psychiatry (2014) 204(5):333-4. doi: 10.1192/bjp.bp.113.136044

45. Eldridge SM, Chan CL, Campbell MJ, Bond CM, Hopewell S, Thabane L, et al. CONSORT 2010 statement: Extension to randomised pilot and feasibility trials. Pilot Feasibility Stud (2016) 2(1):1-32. doi: 10.1186/s40814-016-0105-8

46. Tickle-Degnen L. Nuts and bolts of conducting feasibility studies. Am J Occup Ther (2013) 67(2):161-76. doi: 10.5014/ajot.2013.006270

47. Wood L, Byrne R, Enache G, Morrison AP. A brief cognitive therapy intervention for internalised stigma in acute inpatients who experience psychosis: a feasibility randomised controlled trial. Psychiatry Res (2018) 262:303-10. doi: 10.1016/j.psychres.2017.12.030

48. Nose M, Barbui C, Tansella M. How often do patients with psychosis fail to adhere to treatment programmes? A systematic review. Psychol Med (2003) 33(7):1149-60. doi: 10.1017/S0033291703008328

49. Aust J, Bradshaw T. Mindfulness interventions for psychosis: a systematic review of the literature. J Psychiatr Ment Health Nurs (2017) 24(1):69-83. doi: 10.1111/jpm.12357

50. Chadwick P, Strauss C, Jones AM, Kingdon D, Ellett L, Dannahy L, et al. Group mindfulness-based intervention for distressing voices: a pragmatic randomised controlled trial. Schizophr Res (2016) 175(1-3):168-73. doi: 10.1016/j.schres.2016.04.001

51. Chien WT, Thompson DR. Effects of a mindfulness-based psychoeducation programme for Chinese patients with schizophrenia: 2-year follow-up. $\mathrm{Br} J$ Psychiatry (2014) 205(1):52-9. doi: 10.1192/bjp.bp.113.134635

52. Van de Morthel TF. Faking it: social desirability response bias in self-report research. Aust J Adv Nurs (2008) 25(4):40-8. Available from: http://www. ajan.com.au/Vol25/Vol25-4.pdf.

53. Leon AC. Evolution of psychopharmacology trial design and analysis. J Clin Psychiatry (2011) 72(03):331-40. doi: 10.4088/JCP.10r06669

Conflicts of Interest Statement: The authors declare that the research was conducted in the absence of any commercial or financial relationships that could be construed as a potential conflict of interest.

Copyright (C) 2019 Mediavilla, Muñoz-Sanjose, Rodriguez-Vega, Bayon, Lahera, Palao and Bravo-Ortiz. This is an open-access article distributed under the terms of the Creative Commons Attribution License ( $V C C B Y$ ). The use, distribution or reproduction in other forums is permitted, provided the original author(s) and the copyright owner(s) are credited and that the original publication in this journal is cited, in accordance with accepted academic practice. No use, distribution or reproduction is permitted which does not comply with these terms. 